2

3

4

5

6

7

8

9

\title{
Evolution of proteolytic and physico-chemical characteristics of Norwegian dry-cured ham during its processing
}

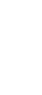
Inna Petrova ${ }^{1}$, Ignat Tolstorebrov ${ }^{1}$, Leticia Mora ${ }^{2}$, Fidel Toldrá ${ }^{* 2}$, Trygve Magne Eikevik $^{1}$

${ }^{1}$ Department of Energy and Process Engineering, Norwegian University of Science and Technology, NO-7491 Trondheim, Norway

${ }^{2}$ Instituto de Agroquímica y Tecnología de Alimentos (CSIC), Avenue Agustí Escardino 7, 46980 Paterna (Valencia), Spain
}

4

17




\section{Abstract}

Proteolytic activity and physico-chemical characteristics were studied for Norwegian drycured ham at four different times of processing: raw hams, post-salted hams (3 months of processing), hams selected in the middle of the production (12 months of processing) and hams at the end of the processing (24 months). Cathepsin $\mathrm{H}$ activity decreased until negligible values after 3 months of processing, whereas cathepsins $\mathrm{B}$ and $\mathrm{B}+\mathrm{L}$ were inactive at 12 months. AAP was the most active aminopeptidase whereas RAP and MAP were active just during the first 12 months of processing. Proteolysis index reached a value of $4.56 \pm 1.03 \%$ with non-significant differences between 12 and 24 months of ripening. Peptide identification by LC-MS/MS was done and two peptides (GVEEPPKGHKGNKK and QAISNNKDQGSY) showing a linear response with the time of processing were found. Unfreezable water content and glass transition temperature were investigated using differential scanning calorimetry (DSC) technique with non-significant differences in the temperature of glass transition for 12 and 24 months of processing.

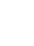

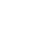

.

50

51

\section{2} 53 54 55 6

7 Keywords: dry-cured ham, proteolysis, muscle enzymes, DSC, peptides 


\section{Introduction}

The production of Norwegian ham is energy and time consuming (up to two years). It is the reason why the product is considered to be in the high price food segment. The demands of Norwegian consumers are growing and the competition with European brands of dry-cured ham is consequently high. Due to this, an urgent need of better understanding of the processes taking place during the manufacture has arisen.

The published information regarding Norwegian dry-cured ham process is limited by a few studies mainly dealing with sensory analysis (Hersleth et al., 2011; Hersleth et al., 2013) or salt distribution processes in hams (Håseth et al., 2012; Vestergaard et al., 2005). Biochemical changes occurring during the processing are mainly responsible for the final quality of drycured ham and therefore processes taking part in the biochemical activity should be investigated. Enzymatic activity is known to contribute to the breakdown of proteins and their degradation products - peptides - mainly by the action of cathepsins and aminopeptidases, respectively (Toldrá, 2002). The knowledge about their activity can be linked to the potential of protein degradation and therefore, it is essential for the processing evaluation.

Some works have focused on the study of peptides as marker compounds of the processing (Gallego et al., 2015; Gallego et al., 2014). Thus, peptide identification can be used as a measure to prove the curing time as well as in the modelling of the proteolytic process. Previous attempts investigated certain stages of the processing (salting, post-salting, final etc.) but did not focus on the evolution of peptides during the whole production. As far as it has not been done before, main objective of the present research was to identify and relatively quantify peptides that can be linked to the protein degradation in order to be implemented into the modelling in a further research.

The other aim of the work is to estimate physico-chemical and thermal properties of the ham which can be linked to the completeness of the processing and quality of the final ham. Thus, 
in the present study the biochemical, physico-chemical and thermal characteristics were used in the characterization of Norwegian dry-cured ham for the first time. Some of the obtained values would result necessary to implement the modelling of the proteolytic process as well as the identification processing time marker peptides.

\section{Materials and methods.}

\subsection{Material and reagents}

Cathepsin fluorescent substrates n-alpha-CBZ-Arg-Arg 7-amido-4-methylcoumarin hydrochloride (N-CBZ-Arg-Arg-AMC), n-CBZ-Phe-Arg 7-amido-4-methylcoumarin hydrochloride (N-CBZ-Phe-Arg-AMC) and Arg 7-amido-4-methylcoumarin hydrochloride (Arg-AMC) were purchased from R\&D Systems (R\&D Systems, Inc., MN, US) as well as the aminopeptidase fluorescent substrates Ala-AMC and Arg-AMC. Reagents for aminopeptidase assays: ethylene glycol tetraacetic acid (EGTA), 2-mercaptoethanol, dithiothreitol (DTT), bestatin, and puromycin as well as sodium citrate, ethylenediaminetetraacetic acid (EDTA), Triton X-100, and cysteine used for cathepsins assays were from Sigma (Sigma-Aldrich CO., US). For peptide identification assays, $\mathrm{HCl}$ at $37 \%$, ethanol, trifluoroacetic acid (TFA), acetonitrile (ACN), and formic acid (FA) from Scharlab (Scharlau Chemie, Barcelona, Spain) were used.

\subsection{Sampling}

A total of twenty-four hams from a cross-breed of 50\% Norwegian Duroc, $25 \%$ Norwegian Landrace and $25 \%$ Yorkshire pork of same age were provided by a local dry-cured ham producer. The raw hams were randomly selected the same day of slaughtering according to their meat content. The values of meat content in the range of $55-65 \%$ were considered suitable.

A total of four groups of six hams representing the four stages of production were studied: raw hams (RH), post-salted hams ( $\mathrm{PSH}, 3$ months of processing), hams selected in the middle 
of the production ( $\mathrm{MH}, 12$ months of processing) and final ripened dry-cured hams $(\mathrm{FH}, 24$ months of processing). Biceps femoris muscle was used in all the analytical determinations which were done each in triplicate.

The processing of the hams was done under same identical conditions and consisted on two stages of salting, one week each, accomplished by sprinkling of hams' cuts. Between the two salting steps, hams were washed and kneaded. The salting was done at $4{ }^{\circ} \mathrm{C}$ and high air relative humidity $(\mathrm{ARH})(\geq 95 \%)$. Salting was followed by a post-salting stage at $8-10{ }^{\circ} \mathrm{C}$ with high ARH ( $\geq 95 \%)$ during 10 weeks. After that, hams were dried during 4 months at 13 ${ }^{\circ} \mathrm{C}$ and $74 \% \mathrm{ARH}$ and finally ripened during at least 17 months at the same temperature and ARH as during the drying step but covered by fat grease.

\section{$2.3 \mathrm{pH}$ measurment}

The raw hams were controlled at 24 hours postmortem in muscle Semimembranosus to check the $\mathrm{pH}$ (691 pH Meter, Metrohm, Switzerland).

\subsection{Moisture content and water activity determination}

For moisture determination the samples were minced and dried at $105{ }^{\circ} \mathrm{C}$ (drying oven DryLine, VWR, Oslo Norway). The bone dry mass (BD) of the muscle was determined by measuring the weight decrease until it reached equilibrium, according to the standard methodology (AOAC, 2012). Water activity measurements were done using an AquaLab CX2 instrument (Decagon Devices, Pullman, WA, USA).

\subsection{Salt content measurement}

Salt content was measured using the conductivity method with a digital salt meter (PALSALT Salt Meter, ATAGO CO. LTD., Tokyo, Japan). All samples were minced, mixed with double-distilled water until $250 \mathrm{~mL}$ at $60{ }^{\circ} \mathrm{C}$, and left for two hours with intensive shaking to obtain aqueous extracts. Then, samples were filtered through glass wool and analyzed by triplicate. 
The enzymatic extraction buffer for cathepsin assays was prepared as described in (Toldrá and Etherington, 1988). For the cathepsin assays, $50 \mathrm{mM}$ of sodium citrate extraction buffer (pH 5) was mixed with $1 \mathrm{mM}$ EDTA and Triton X-100 $0.2 \%(\mathrm{v} / \mathrm{v})$. The fluorometric assay was done according to (Toldrá and Etherington, 1988). Cathepsin B (EC 3.4.22.1) and cathepsin L (EC 3.4.22.15) were tested in $40 \mathrm{mM}$ phosphate reaction buffer ( $\mathrm{pH}$ 6) containing $0.4 \mathrm{mM}$ EDTA and $10 \mathrm{mM}$ cysteine with the addition of fluorescent substrates, namely N-CBZ-ArgArg-AMC $0.05 \mathrm{mM}$ for cathepsin B and N-CBZ-Phe-Arg-AMC $0.05 \mathrm{mM}$ for cathepsins B + consisted of $0.4 \mathrm{mM}$ EDTA, $10 \mathrm{mM}$ cysteine and $0.05 \mathrm{mM}$ Arg-AMC as a fluorescent substrate.

The enzymatic extraction buffer for aminopeptidase assays was described by (Toldrá et al., 2000). Sodium phosphate extraction buffer ( $50 \mathrm{mM}$, pH 7.5) with $5 \mathrm{mM}$ EGTA was used for the aminopeptidase assays. Reaction buffers were $100 \mathrm{mM}$ phosphate extraction buffer $(\mathrm{pH}$ 6.5) containing $2 \mathrm{mM}$ 2-mercaptoethanol and $0.1 \mathrm{mM}$ Ala-AMC for alanyl aminopeptidase (AAP; EC 3.4.11.14) assay; $50 \mathrm{mM}$ phosphate extraction buffer ( $\mathrm{pH} 7.5$ ) containing $0.2 \mathrm{M}$ 3.4.11.6) assay; $100 \mathrm{mM}$ phosphate extraction buffer (pH 6.5) containing $10 \mathrm{mM}$ DTT, 0,15 $\mathrm{mM}$ Ala-AMC and $0.05 \mathrm{mM}$ bestatin for methionylaminopeptidase (MAP; EC 3.4.11.18) assay.

153 For cathepsin assays, $2.5 \mathrm{~g}$ of muscle were homogenized in $25 \mathrm{~mL}$ of sodium citrate 154 extraction buffer (50 mM, pH 5). For aminopeptidase assays, $4 \mathrm{~g}$ of muscle were 155 homogenized in $20 \mathrm{~mL}$ of the sodium phosphate extraction buffer (50 mM, pH 7.5). The extracts for cathepsin and aminopeptidase assays were homogenized using a Polytron homogenizer (PT-MR 2100, Kinematica AG, Luzenerstrasse, Switzerland) three times during 
$10 \mathrm{~s}$ at $26.000 \mathrm{rpm}$ and $4{ }^{\circ} \mathrm{C}$. The resulting homogenates were centrifuged at $10.000 \mathrm{~g}$ for 20

159

160

161

162

163

164

165

166

167

168

169

170

171

172

173

minutes at $4{ }^{\circ} \mathrm{C}$ (Evolution Sorvall ${ }^{\circledast}$ RC, Thermo Fisher Scientific Inc., Waltham, TX, USA).

The supernatants were collected, filtered through glass wool, and stored at $4{ }^{\circ} \mathrm{C}$ until use. The extracts for cathepsin B, cathepsins B $+\mathrm{L}$ and cathepsin $\mathrm{H}$ assays were used without dilution in all cases. The extracts used in the measurement of aminopeptidase activity were diluted using sodium phosphate extraction buffer 1:5 for AAP, and 1:2 for RAP, and used without dilution for MAP when the RH and PSH were analyzed. During the analysis of $\mathrm{MH}$ and FH samples, the extract for AAP, RAP and MAP was used without dilution.

The measurement of cathepsin enzymes and aminopeptidases activity was performed using a fluorescence reader (Fluoroskan Ascent FL, Thermo Electron Corporation Labsystems, Helsinki, Finland). Thus, $250 \mu \mathrm{L}$ of each of the corresponding reaction buffers and substrate and $50 \mu \mathrm{L}$ of the corresponding extract was added to the wells $(\mathrm{n}=4)$, and incubated at $37^{\circ} \mathrm{C}$ during 15 minutes. Fluorescence reading was carried out at 0 and 15 minutes using wavelengths of excitation and emission of $355 \mathrm{~nm}$ and $460 \mathrm{~nm}$, respectively. One unit of enzymatic activity was defined as the amount of enzyme able to hydrolyze $1 \mu \mathrm{mol}$ of substrate per minute at $37^{\circ} \mathrm{C}$. Results were expressed as units (U) per gram of muscle.

\subsection{Proteolysis index measurement}

Proteolysis index was measured as the percentage of mg of leucine divided by the total nitrogen. The amount (mg) of leucine was estimated using the reaction of derivatization with Cd-ninhydrin described by (Doi et al., 1981). The total nitrogen was obtained by Kjeldakhl method using freeze-dried samples by CHN-S/N elemental analyser 1106 (Carlo Erba Instruments s.p.a., Milan, Italy).

Peptide extraction was done according with (Gallego et al., 2015). Briefly, a total of $20 \mathrm{~g}$ of muscle were minced and mixed with $80 \mathrm{~mL}$ of $0.01 \mathrm{~N} \mathrm{HCl}$. The mixtures were homogenized for 8 minutes and centrifuged at $10.000 \mathrm{~g}$ and $4{ }^{\circ} \mathrm{C}$ for 20 minutes. A volume of $250 \mu \mathrm{L}$ was 
taken from the supernatant and three volumes of ethanol $(750 \mu \mathrm{L})$ were added. Finally, the solutions were stored at $4{ }^{\circ} \mathrm{C}$ for 20 hours to precipitate the proteins and centrifuged again at $10.000 \mathrm{~g}$ and $4{ }^{\circ} \mathrm{C}$ for 10 minutes. The supernatants were dried in a rotary evaporator RC10.10 (Jouan, Thermo Fisher Scientific, MA) and in a vacuum-freeze drier. The remained dried extracts were resuspended in $100 \mu \mathrm{L}$ of $\mathrm{H}_{2} \mathrm{O}$ with $0.1 \%$ of TFA for the nLC-MS/MS analysis.

\subsection{Peptide identification by nanoLC-MS/MS}

The analysis of nLC-MS/MS was done according to (Mora et al., 2015) with minor changes. 5 $\mu \mathrm{L}$ of each sample (diluted 1:2 with $0.1 \%$ of trifluoroacetic acid (TFA)) were loaded onto a nanoLC C18-CL trap column $(3 \mu \mathrm{m}, 75 \mu \mathrm{m} \times 15 \mathrm{~cm}$; Eksigent, AB Sciex, CA, USA) and desalted with $0.1 \%$ TFA as a mobile phase A at flow rate of $3 \mu \mathrm{L} / \mathrm{min}$ during $5 \mathrm{~min}$. The trap column was automatically switched in-line onto a nano-HPLC C18-CL capillary analytical column ( $3 \mu$, 75um x 12cm; Nikkyo Technos Co, Ltd. Japan) equilibrated in 5\% acetonitrile $(\mathrm{ACN})$ and $0.1 \%$ formic acid (FA). Peptide elution was carried out with a linear gradient of 5 to $35 \%$ over $120 \mathrm{~min}$ of solvent $\mathrm{B}$, containing $0.1 \% \mathrm{FA}$ in $100 \% \mathrm{ACN}$ at a flow rate of 300 $\mathrm{nL} / \mathrm{min}$. The outlet of the capillary column was directly coupled to a nano-electrospray ionisation system (nano-ESI) and a quadrupole/time-of-flight $(\mathrm{Q} / \mathrm{ToF})$ mass spectrometer (5600 TripleTOF, ABSCIEX). The mass spectrometer was operated in positive polarity and data-dependent acquisition mode, in which a 250-ms TOF MS scan from 350-1250 m/z, was performed, followed by $50-\mathrm{ms}$ product ion scans from $350-1250 \mathrm{~m} / \mathrm{z}$ on the 25 most intense 2-5 charged ions.

ProteinPilot v4.5. search engine (ABSciex) was used to identify the peptide sequences. ProteinPilot default parameters were used to generate a peak list and Paragon algorithm was used to search in Sus scrofa (pig) Expasy protein database using the parameters of no digestion and no cys-alkylation. 
The DSC analysis was done using a DSC Q2000 (TA Instruments, USA) instrument equipped with a Liquid Nitrogen Cooling System (TA Instruments, USA). The temperature and cell constant calibration was done using indium. The heat capacity was calibrated with a sapphire in the range between -150.0 and $150.0^{\circ} \mathrm{C}$. Helium was chosen as a purge gas at $25 \mathrm{~mL}$ x min ${ }^{-}$ ${ }^{1}$ according to manufacturer recommendations. An empty hermetically sealed aluminum pan was used as reference.

Sample (7 - $10 \mathrm{mg}$ ) was placed into aluminum pans with hermetic lids. The pans were sealed with a Tzero® DSC Sample Encapsulation Press (TA Instruments, USA) and placed using an autosampler into the DSC cell. Samples were cooled $\left(10^{\circ} \mathrm{Cxmin}^{-1}\right)$ and equilibrated at -40.0 characterized with the following parameters of the endothermic baseline shift: onset, end and content and the ice fraction. The ice fraction was detected by the integration of DSC melting curve (with the help of sigmoidal tangent baseline function) in the range between the onset of was estimated as a minimum value of the ice melting endothermic peak on the DSC heat flow curve. Straight baselines were drawn from each limit, and S-shaped curve was drawn to 
considering the slope of the heating curve before and after the ice melting peak. The estimation of the mass of ice was calculated with respect to melting enthalpy of ice at different temperatures according to (Tolstorebrov et al., 2014b).

\subsection{Statistical analysis}

The ANOVA (single test) procedure was used to determine significant differences in physicochemical characteristics, enzymatic activities and DSC analysis (glass transition temperature and unfreezable water content) during the different times of processing. The difference was considered significant at $P<0.05$. The homogeneity of variance of the data was tested before applying the ANOVA procedure by employing of Levene's test for all the data. Each statistical analysis was done using the software Microsoft Excel 2010 (Microsoft Office Proffessional Plus 2010) by analyzing six hams per time in triplicate. SigmaPlot 13.0 was used for statistical analysis of the data on peptide identification and drawing all the figures.

\section{Results and discussion}

\subsection{Physicochemical parameters of hams}

The mean of $\mathrm{pH}$ in the raw meat at 24 hours post-mortem ranged between 5.6 and 5.8. The values of moisture content, water activity and salt content were measured for the RH, PSH, MH and FH samples (Table 1). The values of salt content for the pair of RH and PSH and the values of water activity for the pairs of RH and PSH, PSH and $\mathrm{MH}$ and $\mathrm{MH}$ and FH could not be compared by ANOVA because the Levene's test was failed. According to the table, moisture content and water activity values decreased with time. Salt content increased in PSH samples compared with RH as expected. Table 1 shows a significant decrease in moisture content values for the analyzed hams between the $\mathrm{MH}$ and $\mathrm{FH}$ groups $(P<0.05)$ with corresponding differences in water activity values. The salt content rose gradually with time due to the moisture loses occurring in hams during the dry-ripening period with nonsignificant differences between $\mathrm{MH}$ and $\mathrm{FH}$ samples. 


\subsection{Effect of processing time on proteolytic activity}

The activity of endogenous muscle proteolytic enzymes was analyzed for $\mathrm{RH}, \mathrm{PSH}, \mathrm{MH}$, and FH samples to investigate the evolution of cathepsin and aminopeptidase activity during the processing of Norwegian dry-cured ham. The cathepsin activity (cathepsins B, B + L and H) is shown in Figure 1. Standard deviation is shown as error bars; means near one line with different letters differed significantly $(\mathrm{p}<0.05$; ANOVA single test). The values of cathepsin $\mathrm{B}+\mathrm{L}$ for the pair of $\mathrm{MH}$ and $\mathrm{FH}$ and the values of cathepsin $\mathrm{H}$ for the pairs of PSH and $\mathrm{MH}$ and $\mathrm{MH}$ and FH could not be compared by ANOVA because the Levene's test was failed. Cathepsin activity is almost totally suppressed in MH samples (reduced by 97 and $96 \%$ for cathepsins $\mathrm{B}$ and $\mathrm{B}+\mathrm{L}$, respectively, compared with $\mathrm{RH}$ samples), indicating almost no activity after one-year of processing. In fact, other previous studies reported a residual activity of cathepsins B, B + L at the end of ripening for both Biceps femoris and Semimembranosus muscles in Spanish-style dry-cured hams (Armenteros et al., 2012; Parreño et al., 1994; Toldrá and Etherington, 1988). In addition, the activity of cathepsin $\mathrm{H}$ resulted almost totally suppressed in PSH samples (a decrease of $86 \%$ compared with the RH samples), which is in contrast to previously described by (Flores et al., 2009) and (Toldrá and Etherington, 1988) for Iberian (Biceps femoris muscle) and Serrano (Semimembranosus muscle) hams respectively, where cathepsin $\mathrm{H}$ remained active after the post-salting stage, but in agreement with other previously published reports (Armenteros et al., 2012; Parreño et al., 1994) which also showed the reduction of cathepsin $\mathrm{H}$ activity after the post-salting stage. These differences could be due to differences in the processing as well as the used raw material which have been described to highly influence the enzymatic activity during the dry-cured ham processing (Mora et al., 2015). In fact, the fast decrease in the activity of endogenous enzymes observed in Norwegian dry-cured ham can be related to the high $\mathrm{pH}$ of the raw matter, low temperature used, low air relative humidity of the drying air, or even a result of 
several factors (Petrova et al., 2015). The salt content, even though an inhibitor of cathepsins (Rico et al., 1991) and aminopeptidases (Toldrá et al., 1993) is unlikely to be the reason of the activity fall due to the relatively low salt content in the $\mathrm{PSH}, \mathrm{MH}$ and $\mathrm{FH}$ samples.

The activity of aminopeptidases (AAP, MAP and RAP) is shown on Figure 2. Standard deviation is shown as error bars; means near one line with different letters differed significantly ( $p<0.05$; ANOVA single test). The values of AAP for the pair of RH and PSH and the values of MAP for the pair of PSH and MH could not be compared by ANOVA because the Levene's test was failed. The three types of assayed aminopeptidases showed non-significant activity after one year of processing. The activity of RAP and MAP followed a similar trend to cathepsins B and L: they were almost completely inactive in $\mathrm{MH}$ samples (the activity was reduced by $95 \%$ for both RAP and MAP). AAP was active during the whole processing, but its activity was significantly reduced from $\mathrm{MH}$ and $\mathrm{FH}$ samples (reduced by 75 and $78 \%$ correspondingly). In this respect, aminopeptidase activity was detected in Spanish dry-cured ham even after 12 months of processing, suggesting that AAP and RAP may be involved in the latter stages of protein degradation (Toldrá et al., 2000). (Toldrá et al. 2000) showed a good stability of AAP and RAP during dry-curing and both enzymes were suggested to be main contributors to the generation of free amino acids during the processing of dry-cured ham. MAP, whose activity is enhanced in the presence of low amounts of $\mathrm{NaCl}$, can also generate free amino acids in cured meat products. This enzyme has broad substrate specificity, exhibiting maximal activity in the hydrolysis of N-terminal Met (100\%) and Lys (81\%) amino acids (Flores et al., 2000). In this sense, AAP was predictively more active and has been described to be responsible for an important part of porcine muscle aminopeptidase activity during its processing (Petrova et al., 2015; Zhao et al., 2005).

The proteolysis index (PI) during dry-cured ham processing is directly related to the enzymatic activity. In fact, Table 2 shows the PI values of RH, PSH, MH and FH with 
significant differences between RH, PSH and MH samples $(P<0.05)$, while $\mathrm{MH}$ and $\mathrm{FH}$ did not differ statistically $(P>0.05)(n=6)$. Low activity values of proteolytic enzymes would result in low protein degradation and a smaller amount of non-protein nitrogen in the samples.

\subsection{Peptide identification}

The analysis of mass spectrometry resulted in the identification of 6129 peptides. The origin of the peptides was also identified and a total of 229 proteins were determined with $95 \%$ of confidence. The main purpose of the peptide identification was to detect those peptides that could be used as markers of the time of processing. The selection of those peptides showing the potential to be process biomarkers was done as follows: peptide ought to be stable and homogeneous during the manufacture and certain kinetics (negative or positive) of quantitative changes ought to be clearly observed; the dependence of quantitative parameter and time should follow a simple geometrical behavior (a straight line dependence was chosen as the best and simplest alternative) with $R>0.90$ for further modelling. As a quantitative parameter, the intensity of absorbance of the peptide ion was used.

From the total number of identified peptides, two potential candidates to be a biomarker of the manufacturing process of Norwegian dry-cured ham were detected (Table 3): QAISNNKDQGSY peptide is a myosin light chain fragment from Sus scrofa and GVEEPPKGHKGNKK is a fragment of myomesin-1 protein from Sus scrofa, both showing $100 \%$ homology with the origin sequences. Statistically, the values between the time groups of hams differed significantly $(P<0.05)$ probably due to differences in the proteolysis occurred during the processing period.

In order to evaluate the possibility to follow the ripening process through the relative quantification of the generated peptides the $\mathrm{PSH}, \mathrm{MH}$ and $\mathrm{FH}$ samples were taken. The average intensity of those peptides identified using nLS-MS/MS and the time of processing is shown in Figure 3. Standard deviation is shown as error bars; means near one line with 
different letters differed significantly $(P<0.05$; ANOVA single test). Two linear curves of the form $f=y_{0}+a * x$ corresponding with the two graphs of intensity are also shown on the figure together with their equations in order to visualize the linear behavior of the intensitytime dependence.

Several attempts to find potential peptide biomarkers have been previously done in 9 months Spanish dry-cured ham. These peptides resulted to be generated from titin (Gallego et al., 2015) and from protein and LIM-domain protein (Gallego et al., 2014). However, this is the first time that data of intensities of the peptide absorbance for potential biomarkers in relation to the time of processing are showed. The presence of these peptides at $\mathrm{PSH}, \mathrm{MH}$ and $\mathrm{FH}$ make possible to utilize them in the modelling of proteolytic changes. Despite both peptides seems to be adequate, the peptide QAISNNKDQGSY is considered as a prefered candidate to be implemented in the modelling, since the relation between the intensity and time is more pronounced.

\subsection{Differential Scanning Calorimetry results}

Glass transition is a second-order transition from viscous-rubber to brittle-solid state, when cooling down the system. The viscosity of the system reaches a value of $10^{12} \mathrm{~Pa} x \mathrm{~s}$ in a glassy state (Champion et al., 2000). Glass transition in protein food products with high moisture content (usually higher than $25.0 \%$ d.b.) occurs at low and ultra-low temperatures, when a significant amount of water is transited into ice. The temperature of the glass transition differs from product to product and it depends (among other factors) on the average molecular weight of the system. Low average molecular weight will cause a decrease in the glass transition temperature (Roos, 1995). At the same time, the glass transition temperature does not depend on the initial water content of a product (Tolstorebrov et al., 2014b). The so-called unfreezable water, which forms maximal freeze concentrated solution at freezing 
temperatures, influences that phenomenon (Tolstorebrov et al., 2016). The occurrence of the glass transition can be used as an indicator of biochemical changes in foods.

Glass transition of RH samples was detected in the temperature range between -81.78 and $61.73{ }^{\circ} \mathrm{C}$. This data can be referred to relatively high average molecular weight of the maximal freeze concentrated solution in the samples at the beginning of the manufacture. Similar values of glass transition temperatures were previously observed for fresh ham by (Tolstorebrov et al., 2014a). PSH samples showed glass transition in the temperature range between -81.56 and $-65.97{ }^{\circ} \mathrm{C}$ with non-significant statistically differences with $\mathrm{RH}$ samples $(P>0.05)$. The relation between the inflection temperatures of glass transition and the time of production is shown in Figure 4. Standard deviation is shown as error bars; means near one line with different letters differed significantly $(P<0.05$; ANOVA single test $)$.

$\mathrm{MH}$ and FH samples showed a significant decrease in the glass transition temperature in comparison with RH and PSH samples. The values for MH and FH samples decreased to a temperature range between -88.68 and $-74.95{ }^{\circ} \mathrm{C}$ for the onset of glass transition and the end point respectively. This can be explained by the fact that some meat compounds such as proteins are hydrolyzed into small peptides decreasing the average molecular weight of the sample. The glass transition temperatures of $\mathrm{MH}$ and $\mathrm{FH}$ did not differ statistically $(P>0.05)$, probably due to the low enzymatic activity detected after one year of processing. In fact, a strong negative correlation $(\mathrm{R}>-0.97)$ between glass transition temperatures and proteolysis indeces was observed. Thus, the decrease in glass transition temperature was probably due to the decrease in the average molecular weight of the unfrozen (maximal freeze concentration) solution. On the other hand, the influence of salt could also be important since salt molecules (see salt concentration in Table 1) could take part in the formation of the unfreezable solution, as salt crystallization was not reached in the samples (crystallization peak of salt was not detected on the DSC heat flow curves in all the studied samples). According to this, the 
presence of salt could also decrease the average molecular mass of maximal freeze concentrated solution and the temperature of glass transition.

385

386 The amount of unfreezable water was calculated at $26.78 \pm 3.71 \%$ d.b. for RH samples and 28.17 \pm 4.29 for PSH samples $(P>0.05)$, which is in agreement with earlier reports (Pham, 1987; Reid and Fennema, 2007). The evolution of unfreezable water content with time is shown on Figure 5. Standard deviation is shown as error bars; means near one line with different letters differed significantly $(\mathrm{p}<0.05$; ANOVA single test). The curing process resulted in a sharp increase of the unfreezable water content in $\mathrm{MH}$ samples $(38.34 \pm 3.41 \%$ d.b.). A significant increase in the amount of unfreezable water was also observed in $\mathrm{FH}$ samples (45.41 $\pm 5.0 \%$ d.b). The presence of an additional amount of unfreezable water in FH samples should have decreased the average molecular weight of the maximal freeze concentrated solution and, as a consequence, decreased the glass transition temperature. At the same time, non-statistically significant differences in glass transition temperature were detected between the MH and FH groups $(P>0.05)$. Probably some processes involving the aggregation of peptides, lipids etc., are occurring during the curing process. However, such processes were out of the scope of this study. The amount of unfreezable water showed moderate correlation with proteolysis index $(\mathrm{R}>0.91)$.

\section{Conclusions.}

Proteolytic, physico-chemical and thermal characteristics of Norwegian ham were investigated at different times of dry-cured processing (RH, PSH, $\mathrm{MH}$ and $\mathrm{FH}$ samples). Cathepsin $\mathrm{H}$ activity fell down until negligible values after 3 months of the processing, whereas cathepsins $\mathrm{B}$ and $\mathrm{B}+\mathrm{L}$ were almost totally inactivated after 12 months. AAP was the most active aminopeptidase during the whole processing whereas RAP and MAP were only active during 12 months. Proteolysis index values increased up to $4.56 \pm 1.03 \%$ at 24 months of ripening (FH samples) with non-significant differences with the obtained values at 12 
months of ripening (MH samples). Thermal properties showed non-significant differences in the temperature of glass transition for $\mathrm{MH}$ and $\mathrm{FH}$ samples, probably due to similarities in the generated peptides. Two possible marker peptides (GVEEPPKGHKGNKK and QAISNNKDQGSY) showing a linear response with the time of processing were found and their values of absorbance intensity were reported. They will be implemented into the attempts with the modelling of proteolysis index for the processing of Norwegian dry-cured ham.

\section{ACKNOWLEDGEMENTS}

The work was supported by the Research Council of Norway (project 225262/E40 DryMeat), Nortura SA represented by Per Berg, BWL Maskin and Alfsen \& Gunderson. We thank Nortura SA for providing the samples for the experiments and for fruitful discussions during the research. Thanks to the Food Technology Group of NTNU and the Sintef Energy Research represented by Dr. Michael Bantle for their support and cooperation. JAEDOCCSIC postdoctoral contract of L.M. cofounded by the European Social Found is acknowledged. Thanks to IATA (CSIC) for cooperation and especially to the group of Biochemistry, Technology and Innovation of Meat \& Meat Products for all the help and support during the experiments. The proteomic analysis was performed in the proteomics facility of SCSIE at the University of Valencia. The physico-chemical analysis, DSC experiments and the analysis of marker peptides were carried out at NTNU (Norway, Trondheim).

\section{REFERENCES}

AOAC. (2012). Official Methods of Analysis of AOAC International. (19th ed.). Virginia: Association of Official Analytical Chemists.

Armenteros, M., Aristoy, M.-C., Barat, J.M., \& Toldrá, F. (2012). Biochemical and sensory changes in dry-cured ham salted with partial replacements of $\mathrm{NaCl}$ by other chloride salts. Meat science, 90, 361-367.

Champion, D., Le Meste, M., \& Simatos, D. (2000). Towards an improved understanding of glass transition and relaxations in foods: molecular mobility in the glass transition range. Trends in Food Science \& Technology, 11, 41-55. 
Doi, E., Shibata, D. \& Matoba, T., (1981). Modified colorimetric ninhydrin methods for peptidase assay. Analytical Biochemistry, 118, 173-184.

Flores, M., Aristoy, M.C., Antequera, T., Barat, J.M., \& Toldrá, F. (2009). Effect of prefreezing hams on endogenous enzyme activity during the processing of Iberian dry-cured hams. Meat science, 82, 241-246.

Flores, M., Marina, M., \& Toldrá, F. (2000). Purification and characterization of a soluble methionyl aminopeptidase from porcine skeletal muscle. Meat science, 56, 247-254.

Gallego, M., Mora, L., Aristoy, M.C., \& Toldrá, F. (2015). Titin-derived peptides as processing time markers in dry-cured ham. Food Chemistry, 167, 326-339.

Gallego, M., Mora, L., Fraser, P.D., Aristoy, M.-C., \& Toldrá, F. (2014). Degradation of LIM domainbinding protein three during processing of Spanish dry-cured ham. Food Chemistry, 149, 121128.

Hersleth, M., Lengard, V., Verbeke, W., Guerrero, L., \& Næs, T. (2011). Consumers' acceptance of innovations in dry-cured ham: Impact of reduced salt content, prolonged aging time and new origin. Food Quality and Preference, 22, 31-41.

Hersleth, M., Næs, T., Guerrero, L., Claret, A., Recchia, A., Dinnella, C., \& Monteleone, E. (2013). Consumer Perception of Dry-Cured Ham - A Cross-Cultural Study in Italy, Norway and Spain. Journal of Sensory Studies, 28, 450-466.

Håseth, T.T., Sørheim, O., Høy, M., \& Egelandsdal, B. (2012). Use of computed tomography to study raw ham properties and predict salt content and distribution during dry-cured ham production. Meat science, 90, 858-864.

Mora, L., Escudero, E., Arihara, K., \& Toldrá, F. (2015). Antihypertensive effect of peptides naturally generated during Iberian dry-cured ham processing. Food Research International, 78, 71-78.

Parreño, M., Cussó, R., Gil, M., \& Sárraga, C. (1994). Development of cathepsin B, L and H activities and cystatin-like activity during two different manufacturing processes for Spanish dry-cured ham. Food Chemistry, 49, 15-21.

Petrova, I., Aasen, I., Rustad, T., \& Eikevik, T. (2015) Manufacture of dry-cured ham: a review. Part 1. Biochemical changes during the technological process. European Food Research and Technology, 241, 587-599.

Pham, Q.T. (1987). Calculation of Bound Water in Frozen Food. Journal of food science, 52, 210-212.

Reid, D.S., \& Fennema, O. R. (2007). Water and Ice. In: S. Damodaran, K.L. Parkin, \& O.R. Fennema (Eds.), Food Science and Technology (pp. 18-77). (4th ed.). New York: CRC Press.

Rico, E., Toldrá, F. \& Flores, J. (1991) Effect of dry-curing process parameters on pork muscle cathepsins B, $H$ and $L$ activities. Z. Lebensm. Unter. Forsch. 193, 541-544.

Roos, Y. (1995). Characterization of Food Polymers Using State Diagrams. Journal of Food Engineering, 24, 339-360.

Toldrá, F. (2002). Dry-Cured Meat Products. Trumbull: Food and Nutritional Press.

Toldrá, F., Aristoy, M.C., \& Flores, M. (2000). Contribution of muscle aminopeptidases to flavor development in dry-cured ham. Food Research International, 33, 181-185.

Toldrá, F., \& Etherington, D.J. (1988). Examination of cathepsins B, D, H and L activities in dry-cured hams. Meat science, 23, 1-7.

Toldrá, F., Cerveró, M-C. \& Part, C. (1993) Porcine aminopeptidase activity as affected by curing agents. Journal of Food Science 58, 724-726, 747.

Tolstorebrov, I., Bantle, M., \& Eikevik, T.M. (2014a). A DSC study of the thermal properties fo drycured ham. Proseedings of 3rd IIR International Conference on Sustainability and the Cold Chain; 23-25 June 2014, Twickenham, London, UK, pp. 444-451.

Tolstorebrov, I., Eikevik, T.M., \& Bantle, M. (2014b). Thermal phase transitions and mechanical characterization of Atlantic cod muscles at low and ultra-low temperatures. Journal of Food Engineering, 128, 111-118.

Tolstorebrov, I., Eikevik, T.M., \& Bantle, M. (2016). Effect of low and ultra-low temperature applications during freezing and frozen storage on quality parameters for fish. International Journal of Refrigeration, 63, 37-47. 
Figure 1 - Cathepsin-like activity along the processing of Norwegian dry-cured ham.

514 Figure 2 - Aminopeptidase activity along the processing of Norwegian dry-cured ham..

515 Figure 3 - Relative intensity values versus time of ripening of the potential biomarkers 516 identified. cured ham measured by computed tomography and image analysis. Meat science, 69, 9-15.

Zhao, G.M., Zhou, G.H., Tian, W., Xu, X.L., Wang, Y.L., \& Luo, X. (2005). Changes of alanyl aminopeptidase activity and free amino acid contents in biceps femoris during processing of Jinhua ham. Meat science, 71, 612-619. 
517 Figure 4 - Relation between the inflection temperature of glass transition and the time of 518 processing.

519 Figure 5 - Relation between unfreezable water content and the time of processing.

520

521

522

523

524

525

526

527

528

529

530

531

532

533

534

535

536

537 Tables.

538 Table 1. Physico-chemical parameters for the different production time

\begin{tabular}{lccc}
\hline Sample & Moisture content*(w.b.) & Water activity* & Salt concentration*, \% (w. b.) \\
\hline RH & $74.1 \pm 1.11^{\mathrm{a}}$ & $0.99 \pm 0.00$ & $0.20 \pm 0.00$ \\
PSH & $73.4 \pm 1.71^{\mathrm{a}}$ & $0.97 \pm 0.02$ & $0.99 \pm 0.68^{\mathrm{a}}$ \\
MH & $60.9 \pm 3.37^{\mathrm{b}}$ & $0.93 \pm 0.01$ & $4.87 \pm 0.67^{\mathrm{b}}$ \\
FH & $47.7 \pm 2.58^{\mathrm{c}}$ & $0.88 \pm 0.02$ & $5.42 \pm 0.10^{\mathrm{b}}$ \\
\hline
\end{tabular}

539 "The data is indicated as average mean $\pm \mathrm{SD}$; 
541 single test).

542

543

544

545

546

547

548

549

550

551

552

553

554

555

556

557

558

559 Table 2. Proteolysis index for the different production time

\begin{tabular}{lr}
\hline Sample & Proteolysis index, \%* \\
\hline RH & $0.48 \pm 0.15^{\mathrm{a}}$ \\
PSH & $0.28 \pm 1.19^{\mathrm{b}}$ \\
MH & $4.99 \pm 0.57^{\mathrm{c}, \mathrm{d}}$ \\
FH & $4.56 \pm 1.03^{\mathrm{d}}$
\end{tabular}

560 "The data is indicated as average mean $\pm \mathrm{SD}$;

$561^{\text {a-c }}$ Means in the same column with different letters differ significantly $(P<0.05$; ANOVA

562 single test).

563 
Table 3. Potential biomarkers identified using nLC-MS/MS and relatively quantified with a

583 label-free approach.

\begin{tabular}{lccccc}
\hline Peptide & $\begin{array}{c}\text { Molecular } \\
\text { mass }\end{array}$ & $\mathrm{m} / \mathrm{z}$ & $\begin{array}{c}\text { Theoretical } \\
\text { molecular mass }\end{array}$ & $\begin{array}{c}\text { Theoretical } \\
\mathrm{m} / \mathrm{z}\end{array}$ & $\begin{array}{c}\text { Theoretical } \\
\mathrm{z}\end{array}$ \\
\hline GVEEPPKGHKGNKK & 1504.81 & 502.61 & 1504.80 & 502.61 & 3 \\
\hline QAISNNKDQGSY & 1324.59 & 663.30 & 1324.59 & 663.30 & 2 \\
\hline
\end{tabular}

584 "The data is indicated as average mean $\pm \mathrm{SD}$;

$585^{\mathrm{a}-\mathrm{c}}$ Means in the same column with different letters differ significantly $(P<0.05$; ANOVA 586 single test). 


\section{Highlights}

- Proteolytic and physico-chemical characteristics for Norwegian ham were studied

- Thermal properties were studied by DSC teqnique

- Peptide identification by LC-MS/MS was done

- Two marker peptides of the processing were found 
Figure 1

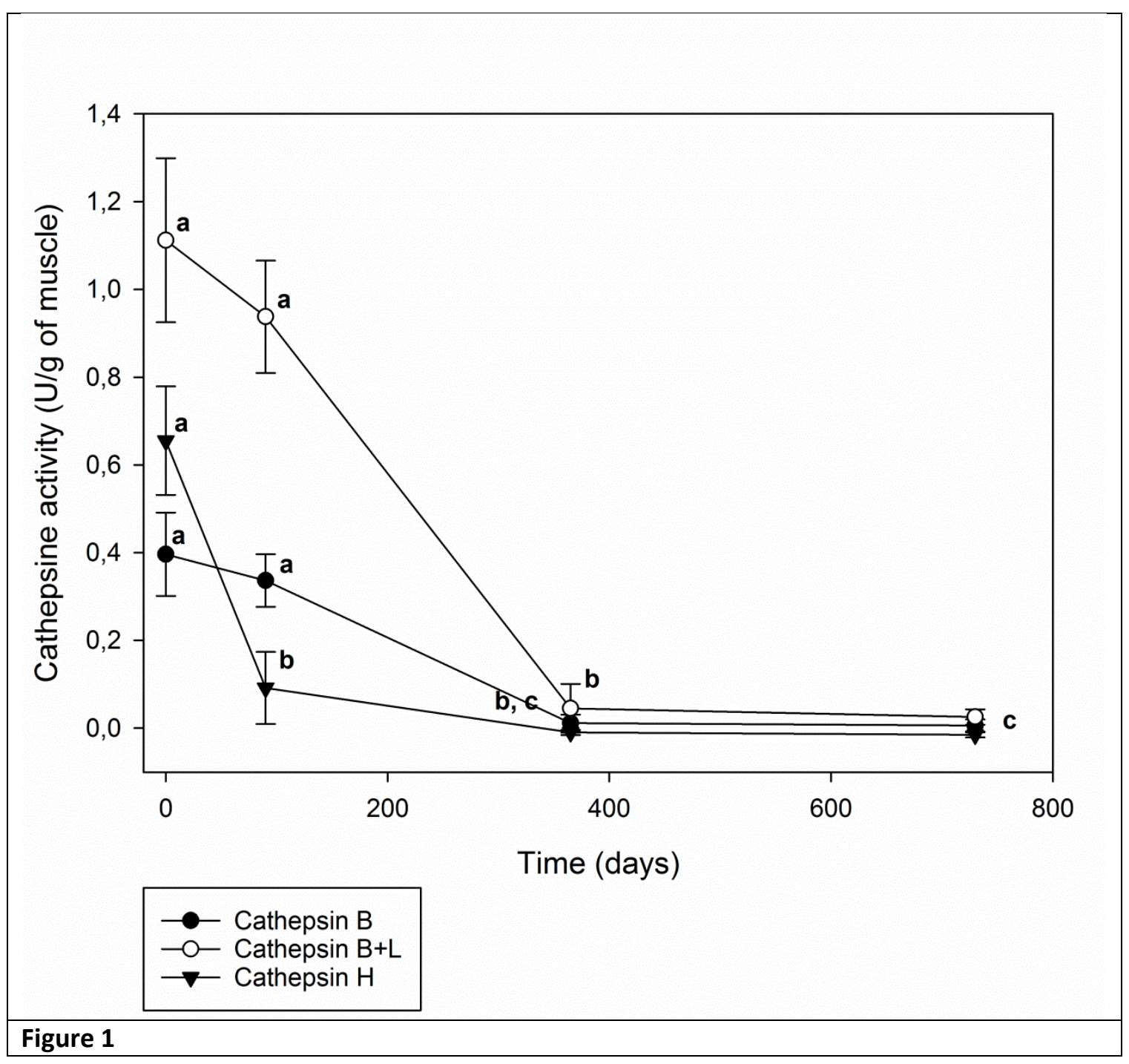


Figure 2

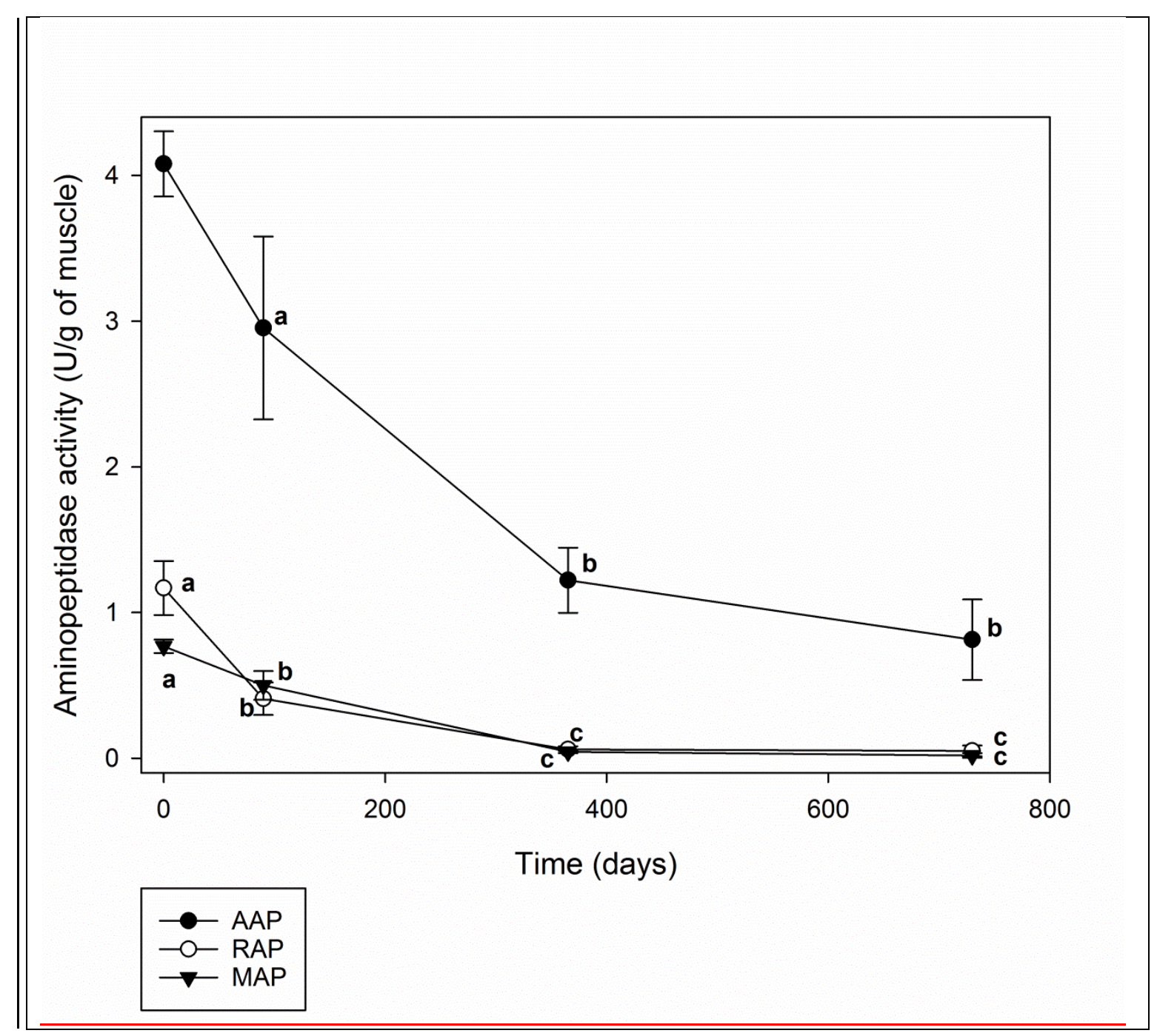




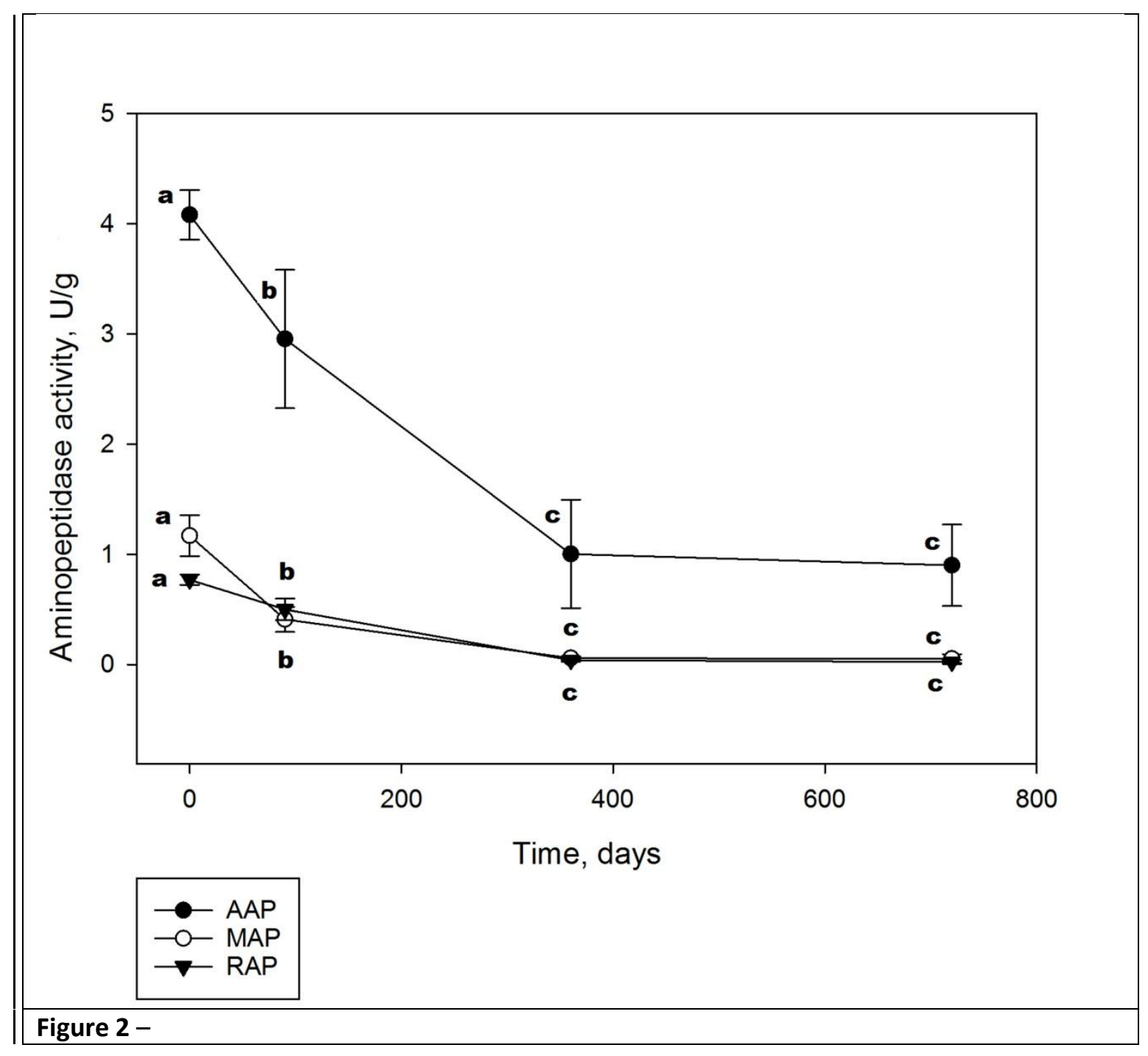


Figure 3

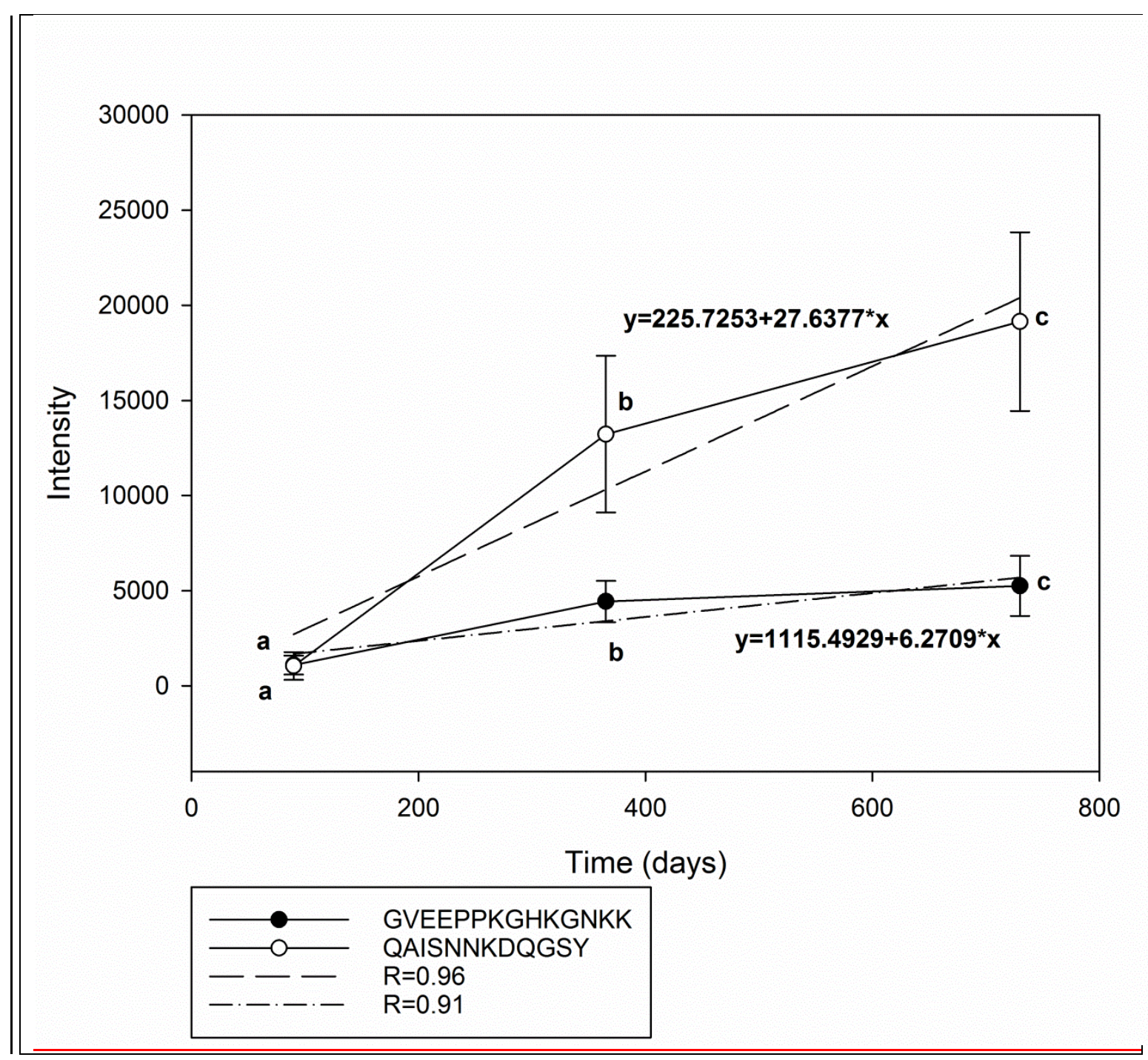




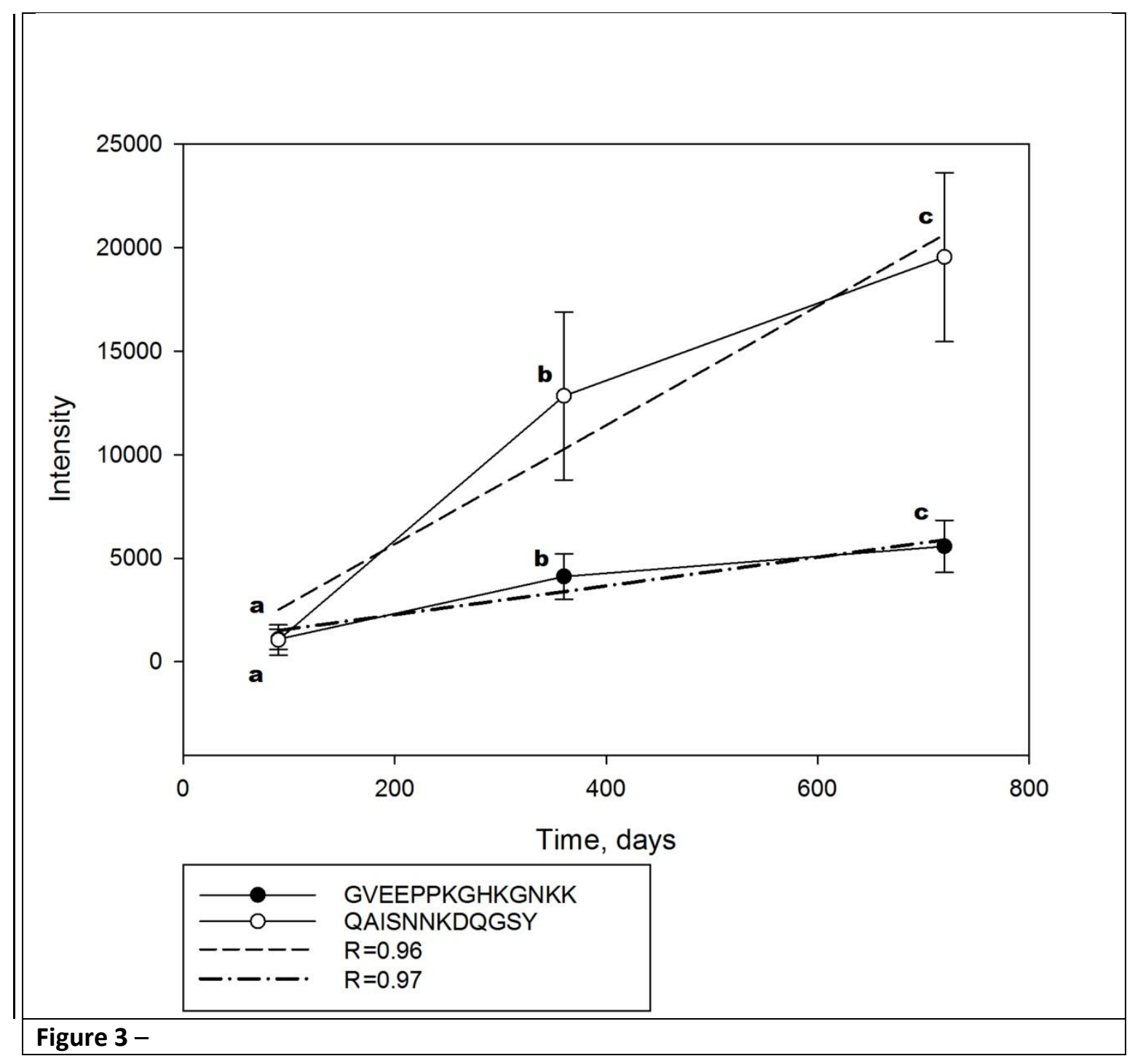


Figure 4
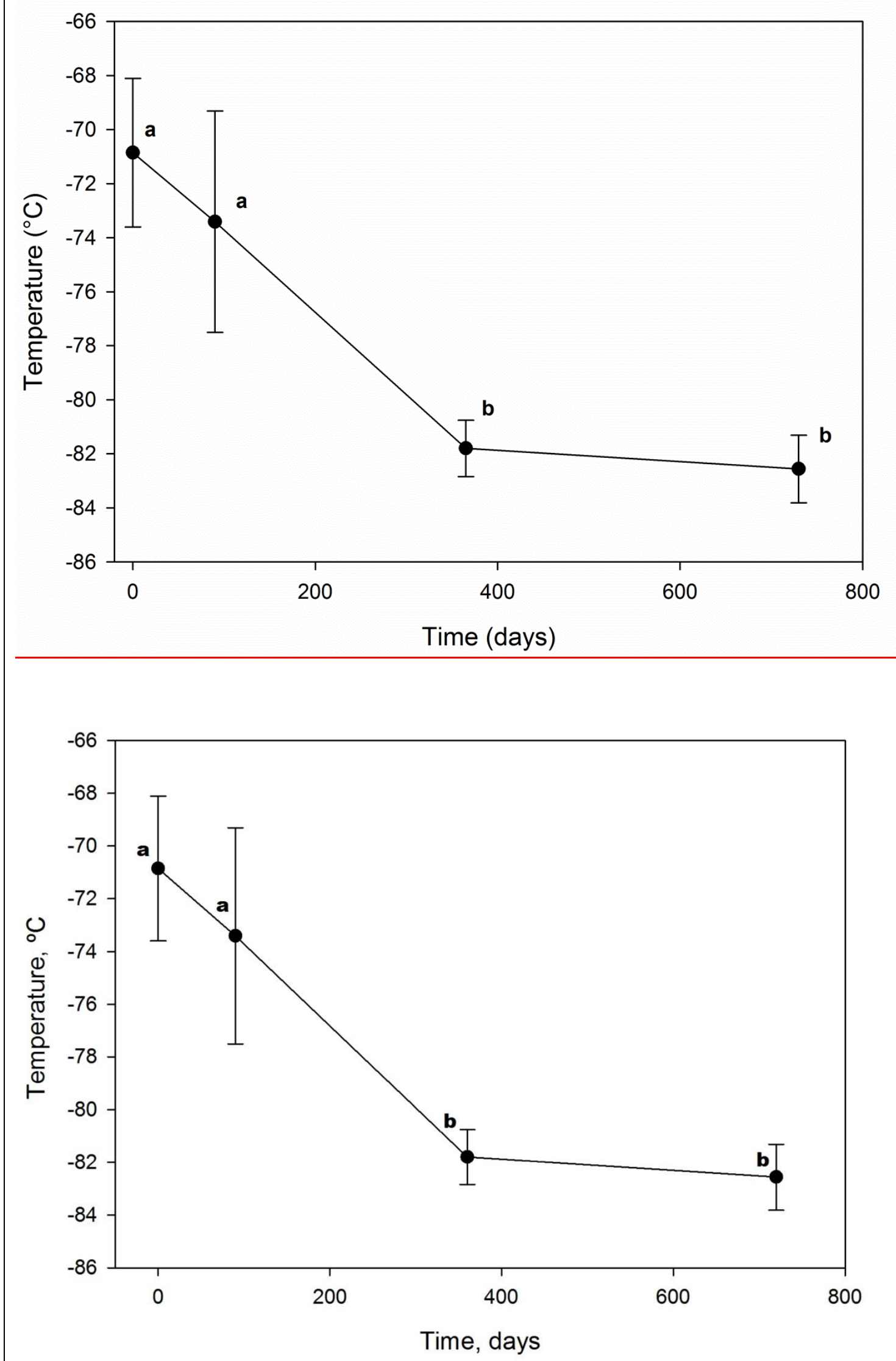
Figure 4- 
Figure 5
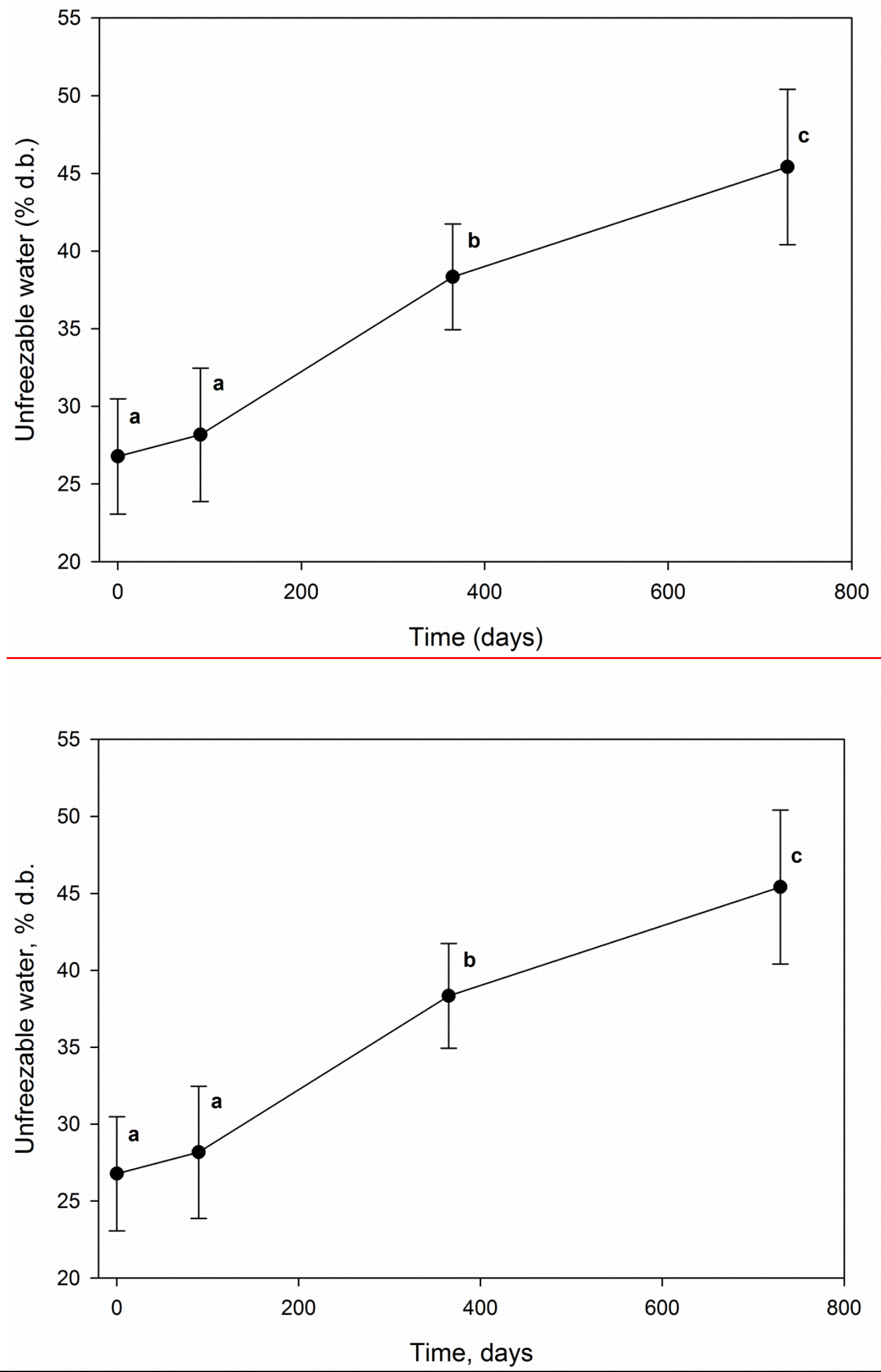

Figure 5 - 
